\title{
TBP Inhibitor Gene
}

National Cancer Institute

\section{Source}

National Cancer Institute. TBP Inhibitor Gene. NCI Thesaurus. Code C20599.

The assembly of transcription complexes at eukaryotic promoters involves a number of distinct steps, including chromatin remodeling and recruitment of a TATA-binding protein (TBP)-containing complexes, the RNA polymerase II holoenzyme. Each of these stages is controlled by positive and negative factors that regulate the interactions of TBP with promoter DNA. The magnitude by which an activated gene is expressed, might depend in part on competition between TBP inhibitors and the holoenzyme for access to the TBP/TATA complex. The first is autorepression, where TBP sequesters its DNA-binding surface through dimerization. Once TBP is bound to DNA, TAF(II)250 and Mot1 induce TBP to dissociate, while NC2 and the NOT complex convert the TBP/DNA complex into an inactive state. TFIIA antagonizes these TBP repressors only in conjunction with the recruitment of the RNA polymerase II holoenzyme by promoter-bound activators. (from PMID 10974559) 